\title{
Production of Extracellular Polymeric Substances by Isolate Consortia Obtained from Mesophilic Aerobic Granules from the Treatment of Paper Mill Effluent
}

\author{
Natalino Perovano Filho, ${ }^{\mathrm{a}}$ Ismarley Lage Horta Morais, ${ }^{\mathrm{b}, *}$ Lívia Carneiro Fidélis Silva, \\ Claudio Mudadu Silva, ${ }^{\mathrm{c}}$ João Carlos Teixeira Dias, ${ }^{\mathrm{a}}$ Cynthia Canedo da Silva, ${ }^{\mathrm{d}}$ and \\ Sérgio Oliveira de Paula ${ }^{\mathrm{d}}$
}

\begin{abstract}
Aerobic granules are large, compact microbial aggregates when compared to flocculent sludge, and they can be used in wastewater treatment. The application of aerobic granular sludge in bioreactors for the treatment of industrial effluents is still considered innovative and has been the subject of several recent studies. In the present study, 19 microbial isolates from mesophilic aerobic granules, obtained from a previous study, were evaluated in co-aggregation tests. The extracellular polymeric substances (EPS) produced, such as carbohydrates, proteins, and humic acids, were determined. The aim was to evaluate the relationship between the amount of EPS produced and the contribution of each isolate in the granulation process. The results of EPS production were used to analyze the polysaccharide / protein (PS / PN) ratio. The consortia with an absence of isolates $4,8,11,14,19$, and 25 presented a PS / PN ratio $<0.5$. These isolates, identified as belonging to the genera Staphylococcus, Agrobacterium, Enterobacter, and Rhodococcus, were considered effective for the production and stability of the mesophilic aerobic granules.
\end{abstract}

Keywords: Aerobic granular sludge; Extracellular polymeric substances; Granule formation; Stability

Contact information: a: Programa de Pós-Graduação em Biologia e Biotecnologia de Microrganismos, Universidade Estadual de Santa Cruz, Campus Soane Nazaré, Salobrinho, Bahia, Brazil; b: Faculdade de Engenharia Civil, Universidade Federal de Uberlândia, Uberlândia, Minas Gerais, Brazil;

c: Departamento Engenharia Florestal, Universidade Federal de Viçosa, Viçosa, Minas Gerais, Brazil; d: Departamento de Microbiologia, Universidade Federal de Viçosa, Viçosa, Minas Gerais, Brazil;

* Corresponding author: ismarley@ufu.br

\section{INTRODUCTION}

The aerobic granular sludge process has increased the efficiency and reduced costs of effluent treatment (Li et al. 2014). The development of aerobic granular sludge treatment has demonstrated that the process can present a highly efficient removal of organic matter and nutrients (Morais et al. 2016a; Wei et al. 2014). The larger size, compact structure, and high biomass retention of aerobic granular sludge (AGS) results in a higher settling velocity, high surface area, dense and porous microbial structure, better filterability, and a high tolerance to organic loads and toxicity when compared to conventional activated sludge (Tay et al. 2002; Toh et al. 2003; Li et al. 2014; Morais et al. 2016a). These advantages in relation to conventional activated sludge have led to an increase of AGS treatment research due to the great potential for municipal and industrial wastewater application (Xie et al. 2019). 
The formation of aerobic granules occurs by microbial aggregation, so aerobic granules can be defined as a mobile biofilm with a gel-like consistency (Weissbrodt et al. 2013).

The production and composition of EPS are important to determine the characteristics of the microbial aggregates in effluent treatment processes (Tay et al. 2002; Xuan et al. 2010). They are essential for the formation of microbial aggregates, since the bacteria are distributed in an EPS matrix. These substances have a structural and protective function for the aggregates and influence porosity, density, surface electric charge, hydrophobicity, mechanical stability, and other biofilm properties (Liu and Tay 2007; Wei et al. 2015).

EPS are a complex high-molecular-weight mixture of polymers, consisting mainly of polysaccharides (PS), proteins (PN), humic-like substances, nucleic acids, lipids, and glycoproteins, which involve bacterial cells and influence the formation and stability of aerobic granules (Gao et al. 2011, Wei et al. 2016). The cohesion of the granular sludge is obtained by increasing both the protein and polysaccharide EPS content (Caudan et al. 2014). The strength of the granules depends on the substrate and growth conditions. Denser granules are formed as a consequence of the growth of microorganisms with a slow growth rate and due to specific interactions involving the EPS of the granule matrix (Caudan et al. 2014).

Aerobic granules can take several weeks to form from activated sludge. Like other treatments, granule formation can be obtained by selecting microbial cultures. The inoculation of microorganisms into the bioreactor can contribute to accelerating granulation and increase granule strength (Ivanov et al. 2006; Adav et al. 2010; Wan et al. 2015). The mixture of a pure culture with high self-aggregation capacity and the activated sludge resulted in the formation of aerobic granules with a mean diameter of $446 \mu \mathrm{m}$ after only 8 days of cultivation (Ivanov et al. 2006). Bacteria of the genus Sphingomonas sp. were present at the beginning of granulation in sequential batch reactors (SBR) fed with synthetic effluent, contributing to the maintenance of granule structure and functioning (Wan et al. 2016).

Interactions between aggregated bacteria facilitate metabolic interactions, intercellular communication, and genetic exchanges between cells (Maszenan et al. 2011). Studies have suggested that the physical characteristics of granules depend on the diversity of the microbial communities and the composition of the EPS associated with these communities (Caudan et al. 2014). Although the characteristics and dynamics of EPS are well-known in conventional activated sludge systems, information about these characteristics and dynamics in AGS systems is scarce (Xie et al. 2019; Zhang et al. 2019). Such information may contribute to a stable operation of AGS process.

In a previous study, the microorganisms found in the aerobic granular sludge that contributed to microbial aggregation and the increase of the mechanical resistance of the granules were determined. Nineteen strains were isolated from an aerobic granular sludge formed in an SBR treating paper mill effluent. The formation of the granules was obtained by microbial selection. Co-aggregation tests indicated that some isolates $(2,7,9,13$, and 25) improved granule formation, while others $(10,14,18$, and 26) inhibited granulation (Morais et al. 2016b).

The objectives of the present study were to quantify the main components of the extracellular polymeric substances produced by microorganism consortia isolated in the aerobic mesophilic granulation process and to identify microorganisms that produce EPS that favor the formation of aerobic granule mesophilic cells. 


\section{EXPERIMENTAL}

\section{Methodology}

Bacterial isolates from mesophilic granules

The mesophilic aerobic granules were obtained in a sequential batch reactor (SBR), fed with recycled paper mill effluent (Morais et al. 2016b).

Aliquots of $5 \mathrm{~mL}$ of granular sludge were submitted to three centrifugation steps at $650 \mathrm{~g}$ for $2 \mathrm{~min}$. After each centrifugation, the supernatant was discarded and the pellet resuspended in $0.85 \%$ saline. At the end of the third centrifugation, the samples were subjected to ultrasonic pulses $(20 \mathrm{kHz}, 4 \mathrm{~s})$ for sludge disintegration using the Ultrasonic homogenizer-Cole Palmer Instrument Company 4710 series Chicago Illinois 60648.

The samples disaggregated using the ultrasound were centrifuged (650 g, $2 \mathrm{~min})$, and aliquots of $100 \mu \mathrm{L}$ of the supernatant were removed to obtain serial dilutions of $10^{-1}$ to $10^{-9}$.

Samples of $100 \mu \mathrm{L}$ of each dilution were inoculated into Petri dishes containing solid R2A medium $(0.5 \mathrm{~g}$ of hydrolyzed casein, $0.5 \mathrm{~g}$ of yeast extract, $0.5 \mathrm{~g}$ of peptone, 0.5 $\mathrm{g}$ of dextrose, $0.3 \mathrm{~g}$ of Dipotassium phosphate, $0.024 \mathrm{~g}$ of magnesium sulfate, $0.3 \mathrm{~g}$ of sodium pyruvate, $15.0 \mathrm{~g}$ of agar, and $1000 \mathrm{~mL}$ of distilled water). The plates were maintained at room temperature, and the resulting colonies were picked, spread on solid R2A media, and the purified colonies were isolated. Each pure culture was inoculated into liquid R2A medium and stored in ultra-freezer at $-80^{\circ} \mathrm{C}$.

\section{Identification of the isolates: DNA extraction}

The isolates were inoculated into microtubes $(2.0 \mathrm{~mL})$ containing $1 \mathrm{~mL}$ of liquid TY medium (5g of Tryptone, $3 \mathrm{~g}$ of yeast extract, $0.9 \mathrm{~g}$ of calcium chloride dihydrate and $1000 \mathrm{~mL}$ of distilled water). The DNA extraction was performed after $24 \mathrm{~h}$ of incubation, according to the methodology described by Kennedy et al. (2008), with modifications. One $\mathrm{mL}$ of the lysis buffer (100 mM EDTA, $100 \mathrm{mMTris}-\mathrm{HCl}, 2 \%$ CTAB, $1 \%$ SDS, and 1.5 $\mathrm{M} \mathrm{NaCl}$ ) was added to each culture. The reaction mixture was homogenized in a vortex and heated for $20 \mathrm{~min}$ in a water bath at $65^{\circ} \mathrm{C}$ (mixed every $5 \mathrm{~min}$ ). The mixture was then centrifuged for $20 \mathrm{~min}$ at $2800 \mathrm{~g}$. The aqueous phase was transferred to another microtube $(2.0 \mathrm{~mL})$ and the phenol: chloroform: isoamyl alcohol (25:24:1) solution was added to the same volume as that collected and vortexed for $1 \mathrm{~min}$, followed by centrifugation for 10 $\mathrm{min}$ at $2800 \mathrm{~g}$. The supernatant was transferred to another microtube $(2.0 \mathrm{~mL})$, and 0.7 volume of isopropanol (100\%) and 0.1 volume of $3 \mathrm{M}$ sodium acetate were added. The tubes were shaken 10 times and incubated at $-20{ }^{\circ} \mathrm{C}$ for approximately 12 hours. The tubes were centrifuged three times for $10 \mathrm{~min}$ at $2800 \mathrm{~g}$, discarding the supernatant, followed by washing the pellet with $70 \%$ alcohol and further centrifugation. The pellet was allowed to dry and then resuspended in $40 \mu \mathrm{L}$ of sterile Milli-Q water.

\section{DNA amplification}

DNA from each isolate was amplified with the primers 27F (5'-AGAGTTTGATCMTGGCTCAG-3') and 1525R (5'-AAGGAGGTGATCCAGCC-3'). The PCR mixture contained $0.3 \mu \mathrm{L}$ of Taq DNA polymerase (Invitrogen, Carlsbad, CA, USA), 0.5 $\mu \mathrm{L}$ of each primer $(10 \mu \mathrm{M}), 2.5 \mu \mathrm{L}$ of the $10 \mathrm{X}$ reaction buffer, $0.5 \mu \mathrm{L}$ Of dNTP's $(10 \mathrm{mM})$, $1.5 \mu \mathrm{L} \mathrm{MgCl} 2(50 \mathrm{mM}), 1 \mu \mathrm{L}$ of the DNA sample, and $18.2 \mu \mathrm{L}$ of sterile Milli-Q water per sample. The amplification was performed with a thermocycler (Mastercycler Personal, Eppendorf, Hamburg, Germany) under the conditions: $94{ }^{\circ} \mathrm{C}$ for $5 \mathrm{~min}$, followed by 14 
cycles $\left(94{ }^{\circ} \mathrm{C}\right.$ for $30 \mathrm{~s}, 65^{\circ} \mathrm{C}$ for $40 \mathrm{~s}$, and $72{ }^{\circ} \mathrm{C}$ for $1 \mathrm{~min}$ ), 15 cycles $\left(94{ }^{\circ} \mathrm{C}\right.$ for $30 \mathrm{~s}, 50$ ${ }^{\circ} \mathrm{C}$ for $40 \mathrm{~s}$, and $72{ }^{\circ} \mathrm{C}$ for $1 \mathrm{~min}$ ), and finished with extension at $72{ }^{\circ} \mathrm{C}$ for $7 \mathrm{~min}$.

The amplicons were sequenced by ACTGene Laboratory (Biotechnology Center, Federal University of Rio Grande do Sul, Porto Alegre, Brazil) using an ABI-Prism 3100 Genetic Analyzer with $50 \mathrm{~cm}$ capillaries and POP6 polymer (Applied Biosystems 2016).

Sequence analysis was performed with the MEGA (V. 6.0) and Bioedit, and compared to the GenBank database using BLAST (NCBI 2015) for isolate identification.

\section{Co-aggregation index with absence of an isolate}

Twenty co-aggregation assays were carried out from consortia of the isolates, one containing all 19 isolates and used as the control, and 19 other consortia lacking one particular isolate at a time. The consortium with all the isolates was called the control and the others were identified by "- $n$ " which indicates the isolate absent from the consortium. For example, the consortium "-1" signifies the combination of 18 isolates but lacking isolate 1, and so on.

Each isolate was initially inoculated into liquid R2A medium and incubated at 30 $\pm 1{ }^{\circ} \mathrm{C}$ under shaking $(110 \pm 10 \mathrm{rpm})$ for $48 \mathrm{~h}$.

Aliquots of the liquid cultures for each isolate, with optical density (OD) equal to $1.00 \mathrm{~mL}^{-1}(\lambda=600 \mathrm{~nm})$, were inoculated into $75 \mathrm{~mL}$ of liquid $\mathrm{R} 2 \mathrm{~A}$ medium in $250 \mathrm{~mL}$ Erlenmeyers. The consortia were incubated at $30 \pm 1{ }^{\circ} \mathrm{C}$ with shaking $(110 \pm 10 \mathrm{rpm})$ and $5 \mathrm{ml}$ samples of each Erlenmeyer were taken after 2, 4, 8, 24, 48, and $72 \mathrm{~h}$ of incubation. The OD were measured $(\lambda=600 \mathrm{~nm})$ and the samples stored for EPS extraction and analysis.

\section{EPS extraction and analysis}

One $\mathrm{mL}$ of each sample was transferred to microtubes $(2.0 \mathrm{~mL})$, centrifuged $(11200$ $\left.\mathrm{g}, 4{ }^{\circ} \mathrm{C}, 15 \mathrm{~min}\right)$, and the supernatant stored in another microtube for quantification of free EPS. The pellets were resuspended in $20 \mathrm{~mL}$ of phosphate buffer. The $\mathrm{pH}$ was adjusted to 11 by the $1 \mathrm{M} \mathrm{NaOH}$, followed by heating $\left(80{ }^{\circ} \mathrm{C}, 30 \mathrm{~min}\right)$. After this extraction step, the samples were centrifuged $\left(11200 \mathrm{~g}, 4{ }^{\circ} \mathrm{C}, 10 \mathrm{~min}\right)$ and the supernatant stored for further analysis of the bound-EPS (McSwain et al. 2005).

The chemical characterization of the EPS was carried out through the carbohydrate, protein and humic acid content analysis.

The EPS content of the aggregates was measured in each consortia of isolates and performed in triplicate.

\section{Carbohydrate quantification}

The phenol-sulfuric acid dosing method was used in which $0.25 \mathrm{~mL}$ of phenol $(5 \%)$ and $1.25 \mathrm{~mL}$ of sulfuric acid were added in $0.5 \mathrm{~mL}$ of each sample. After 10 minutes, the tubes were shaken and placed in an ice bath for 20 minutes. The calibration curve using sucrose (0-1.0 mg.mL $\left.\mathrm{mL}^{-1}\right)$ was used as the standard. Absorbance values were measured in a spectrophotometer at $490 \mathrm{~nm}$ (Albalasmeh et al. 2013).

\section{Proteins and humic acids quantification}

The modified Lowry method was used (Frolund et al. 1996), with two reagents (A and $\mathrm{B}$ ) for the reactions. Reagent $\mathrm{A}$ was produced by the addition of three solutions in the ratio of 1:1:100 (1-35 g.L $\mathrm{L}^{-1}$ of $\mathrm{CuSO} 4,2-70$ g. $\mathrm{L}^{-1}$ of $\mathrm{KNaC}_{4} \mathrm{H}_{4} \mathrm{O}_{6}: 4 \mathrm{H}_{2} \mathrm{O}$ solution and 3-70 g. $\mathrm{L}^{-1}$ of $\mathrm{Na}_{2} \mathrm{CO}_{3}$ ). Reagent $\mathrm{B}$ was produced with a composition similar to reagent $\mathrm{A}$ except 
for replacing the $\mathrm{CuSO} 4$ solution by deionized water. In the reactions, the Folin-Ciocalteau reagent $(2 \mathrm{~N})$ diluted 10 times was also used.

The solutions were added in the following sequence: sample: Reagent A: Folin Reagent in the ratio 1:1:1. The reaction mixture was shaken, and after $30 \mathrm{~min}$ absorbance was measured in a spectrophotometer at $750 \mathrm{~nm}$. The same procedure was carried out with Reagent B. A calibration curve of $0-1.0 \mathrm{mg} \cdot \mathrm{mL}^{-1}$ of albumin was used as the control.

For the protein determination the Eq. 1 was used:

$$
A b s_{\text {proteins }}=1.25 \cdot\left(A b s_{A^{-}} A b s_{B}\right)
$$

The determination of humic acids was performed using Eq. 2:

$$
A b s_{\text {humic acids }}=A b s_{B}-\left(0.2 \cdot A b s_{\text {protein }}\right)
$$

\section{Total Organic Carbon (TOC) determination}

TOC was determined by the catalytic oxidation method (Xuan et al. 2010) with a carbon analyzer (Shimadzu® 2016).

\section{RESULTS AND DISCUSSION}

\section{Isolate identification}

Nineteen bacterial isolates were obtained and identified (Table 1), belonging to five bacterial genera. Only isolate 3 could not be identified.

Table 1. Identification of the Isolates Obtained from the Mesophilic Aerobic Granules formed in the Treatment of Recycled Paper Mill Effluents

\begin{tabular}{|c|c|}
\hline Isolates & Genus \\
\hline $1,4,5,10,15,18$ and 23 & Acinetobacter \\
\hline 2,13 and 19 & Agrobacterium \\
\hline 3 & ------- \\
\hline $7,8,11,14,24$ e 26 & Enterobacter \\
\hline 9 & Staphylococcus \\
\hline 25 & Rhodococcus \\
\hline
\end{tabular}

\section{Coaggregation Assay}

The importance of each isolate in the granule formation process and its ability to coaggregate with the others was evaluated in a prior study (Morais et al. 2016b).

Combinations in which the isolates 4, 10, 14, 18, and 26 were absent formed larger aggregates than the control. This could indicate that these isolates inhibit granulation and, in their absence, the important bacteria for granule formation can increase in number, leading to the development of larger aggregates.

The absence of isolates 2, 7, 9, 13, 19, and 25 resulted in small aggregates or an absence of visible aggregates, indicating that these isolates may be important in the process and their presence may contribute to the formation of aerobic granules. 


\section{Optical Density of Consortiums}

Optical density (OD) is one of the techniques commonly used to estimate cell concentration in liquid cultures (Myers et al. 2013). The consortia showed minimal alterations in OD between 48-72 h (Fig. 1), demonstrating the continuation of microbial growth, which can lead to the production or release of EPS that may favor the formation of mesophilic aerobic granules.

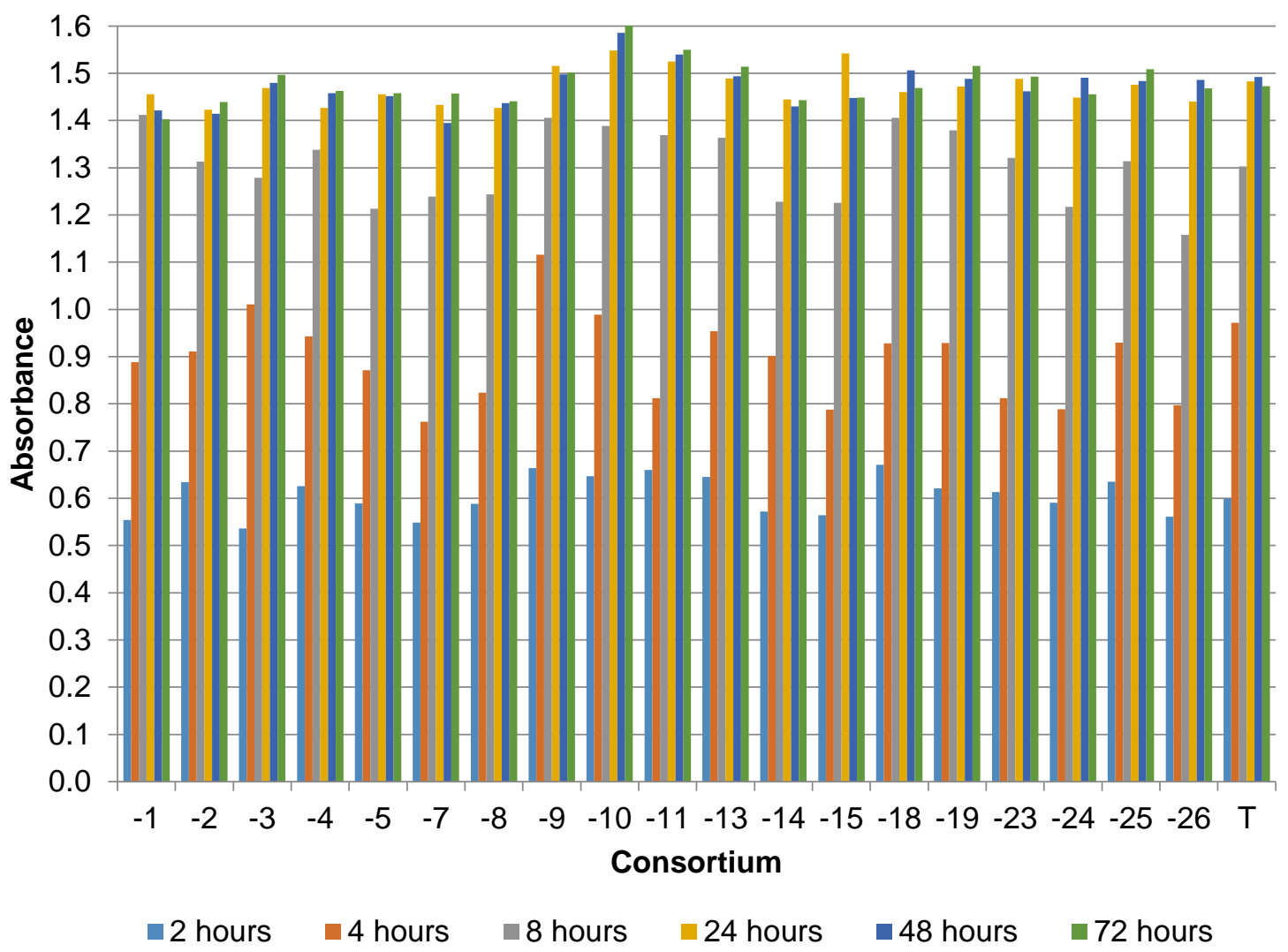

Fig. 1. Absorbance of samples of each consortium during co-aggregation experiment. Optical density $(\lambda=600 \mathrm{~nm}) .\left(-n=\right.$ consortium with absence of the $\mathrm{n}^{\text {th }}$ isolate, $T=$ control consortium with all isolates).

Optical density measurement is a fast and reliable method, but it is based on the assumption that bacteria grow as single cells of equal size and that the cells are uniformly dispersed in the liquid culture (Haaber et al. 2016). In the case of cultures forming clusters of cells with a three-dimensional structure, the correlation between the optical density data and the number of cells must be verified, since part of the biomass can cover internal layers of cells (De Carvalho et al. 2005). Other challenges that may potentially affect the measurement of optical density include viable but uncultured cells or non-viable but intact cells present in the culture as well as cells in the dividing process (Haaber et al. 2016).

In a bioreactor, the optical density is correlated with the concentration of volatile suspended solids in the aeration tank (SSVTA). The OD followed the variations of the SSVTA during the process of aerobic granule formation in an SBR for the treatment of 2,4-dichlorophenol (Khan et al. 2011). Additionally, the presence of toxic substances inhibits growth and reduces OD. The addition of $2 \mathrm{mg} . \mathrm{L}^{-1}$ and $3 \mathrm{mg} . \mathrm{L}^{-1}$ of $\mathrm{Cr}^{6+}$ caused a 
reduction in OD of 1.0 to 0.8 and 0.3 , respectively (Yang et al. 2016), while the addition of $3.5 \mathrm{mM}$ of sodium dodecyl sulfate caused an OD decrease from 1 to 0.2 within only 30 minutes of incubation (Klebensberger et al. 2006).

\section{EPS Determination}

\section{Carbohydrate content}

The consortia with the absence of isolates 5, 7, 13, 15, 19, 24, 25, and 26 presented carbohydrate production between 48 and $72 \mathrm{~h}$ (Fig. 2).

In the studies developed by (Morais et al. 2016b) isolates 2, 7, 9, 13, 19, and 25 were indicated as being favorable for aggregate formation. In general, the consortia with an absence of isolates indicated as contributing to aggregate formation maintained or increased carbohydrate production between 48 and 72 h (Fig. 2).

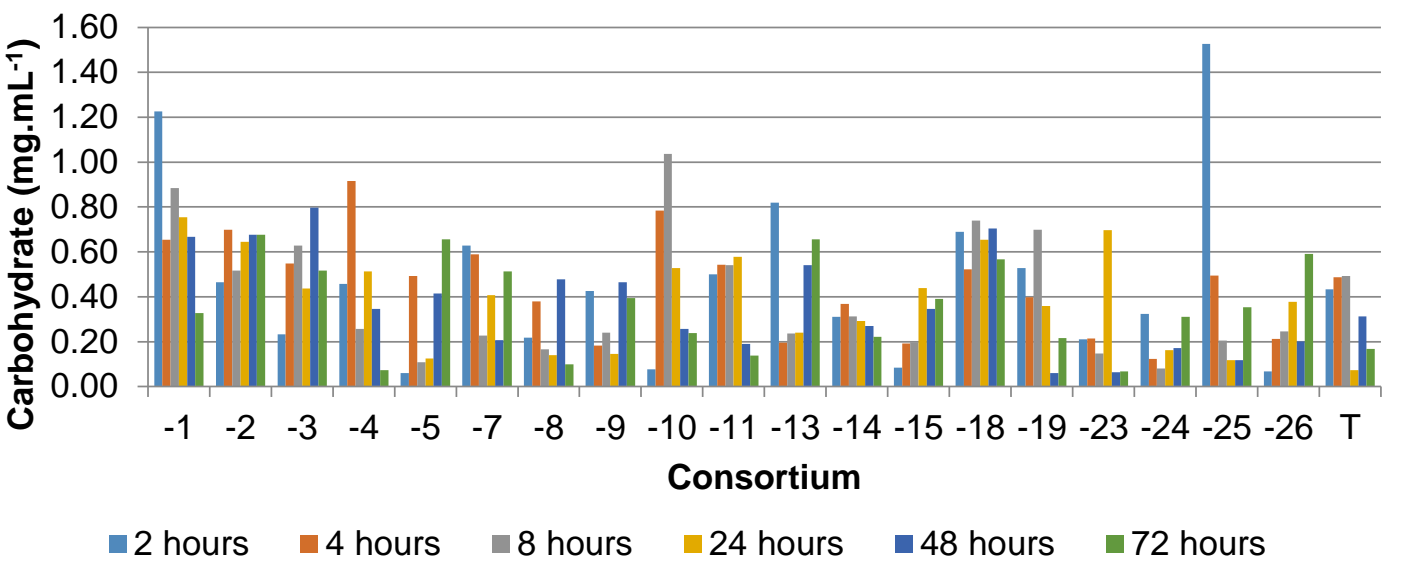

Fig. 2. Carbohydrate concentration (mEq. $\mathrm{mL}^{-1}$ of sucrose) during co-aggregation experiment. $(-n=$ consortium with absence of the $\mathrm{n}^{\text {th }}$ isolate, $\mathrm{T}=$ control consortium with all isolates)

Therefore, these isolates can impair the formation of granules, because the polymeric polysaccharides act, mainly, in the adhesion of the bacteria favoring the formation of micro-colonies. Polysaccharides serve as bridges or connections between smaller granules, favoring the formation of larger granules (Jiang et al. 2002; Liu et al. 2004). On the other hand, carbohydrates are hydrophilic components of EPS and excess carbohydrate production (especially when coupled with a low protein/carbohydrate ratio) results in an increase in the absolute value of zeta potential, impairing the formation of granules (Tu et al. 2010). Thus, the isolates indicated as harmful to the granulation process may have reduced the formation of aggregates due to their higher production of carbohydrates.

The reduction in carbohydrate content observed in some consortia may be associated with their use as a carbon source by the bacteria present in the consortia for their metabolic activity (Zhang et al. 1999). The consortia -4, -10, -14, and -18, which lack the aggregates harmful to the granulation process (aggregates 4, 10, 14, 18, and 26), showed a rapid increase in carbohydrate content at the initial stage (reduction of microbial growth after $48 \mathrm{~h}$, as presented in the OD results). This behavior is similar to that observed by Xie et al. (2019). The reduced carbohydrate content observed in some consortia may be associated with its use as a carbon source by the bacteria present in the consortia for their metabolic activity (Zhang et al. 1999). At the beginning of the granulation process, the 
sludge tends to produce more EPS as a way of increasing the aggregate's size and reducing the selective sludge washout pressure. Polysaccharides play an important role in this process of formation of large-sized aggregates and, therefore, these substances increase significantly. However, after aggregate formation and maturation, oxygen and substrate deficiency in the core regions of the granules leads to the utilization and reduction of the more easily biodegradable EPS compounds, mainly polysaccharides (Xie et al. 2019).

According to Seviour et al. (2012), aerobic granules contain a multispecific microbial community, which synthesizes a great diversity of exopolysaccharides that play a structural role and are distinguished from the conventional activated sludge by the presence of gelatinous exopolysaccharides.

The granular sludge settleability is related to the amount of EPS produced (Kim et al. 2014). Polysaccharides are important for granule formation, but the stability of the granules depends on the protein core (Zhu et al. 2015). The amount of EPS depends, among other factors, on the microbial community present in the granule and on the reactor operating conditions. The decrease in the sedimentation time caused the loss of the microorganisms by means of slow sedimentation and an increase in the microbial community with good flocculation, which resulted in the rapid increase of protein (PN) and polysaccharides (PS) levels. However, with granular sludge maturation, the PS content decreased due to the consumption of the polysaccharides by the microorganisms during the starvation phase (Zhu et al. 2012).

\section{Protein content}

The consortia that presented an absence of the isolates 2, 4, 5, 8, 23, 25, and 26, showed protein production between 48 and $72 \mathrm{~h}$ (Fig. 3).

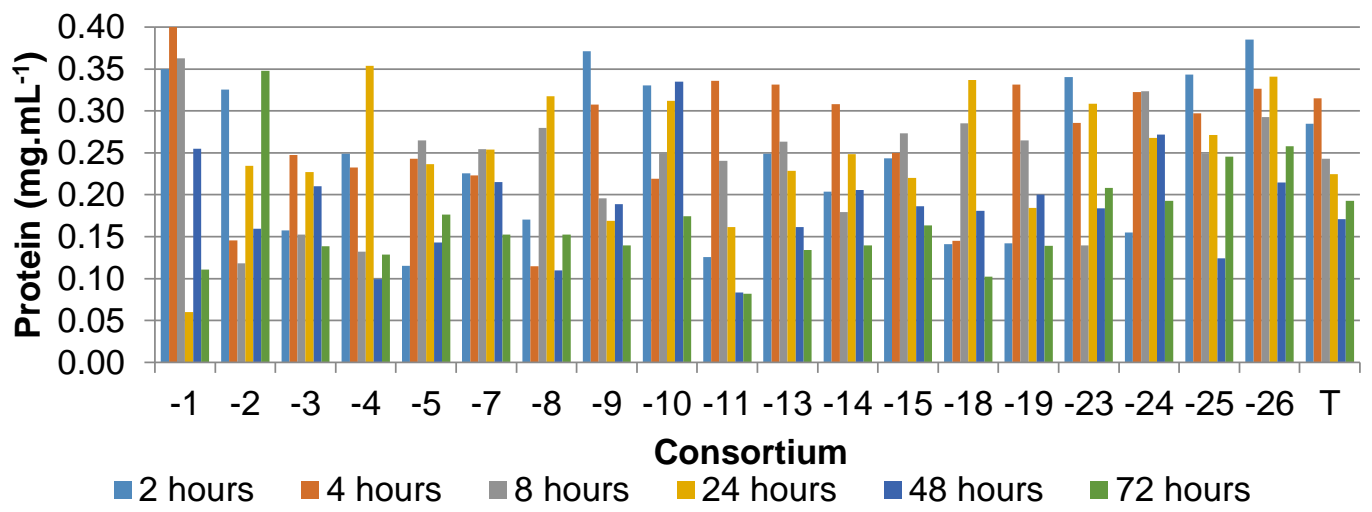

Fig. 3. Concentration of proteins (mEq. $\mathrm{mL}^{-1}$ of albumin) during co-aggregation experiment. $(-\mathrm{n}=$ consortium with absence of the $\mathrm{n}^{\text {th }}$ isolate, $\mathrm{T}=$ control consortium with all isolates)

Consortia lacking four isolates (7, 9, 13, and 19) (Fig. 3), indicated as contributors to the formation of aggregates in the previous study (Morais et al. 2016b), showed a decrease in protein content. This may indicate that these isolates can act by maintaining or increasing protein concentration and favoring the formation of more stable aerobic granules.

The absence of these isolates can inhibit the formation of granules with greater stability, since the proteins are responsible for the formation and structural stability of the granules (McSwain et al. 2005; Di Laconi et al. 2006; Tu et al. 2010). 
The protein content of aerobic and anaerobic granular sludge is higher than observed in flocculent sludge and presents a negative linear correlation with sludge surface loading, favoring the formation of granules (Zhu et al. 2015). The amount of polysaccharides and proteins in the EPS of the granular sludge is approximately 1.3 to 2.8 times greater than the conventional activated sludge content (Wei et al. 2018).

The reduction of the protein content observed in some consortia may also be associated with their hydrolysis and partial utilization by microorganisms present in the consortia for their metabolic activity, especially in the endogenous decay phase (Zhang et al. 1999; Wei et al. 2018).

The proteins are hydrophobic constituents of the EPS and contribute to a decrease in the zeta potential, favoring formation, as well as increasing the structural stability of the granules (McSwain et al. 2005; Di Laconi et al. 2006; Tu et al. 2010). The high content of negatively charged amino acids of the proteins contributes to the greater amount of electrostatic bonds with the multivalent cations in stabilizing aggregate structures (Wei et al. 2018). Thus, tryptophan and protein-like substances are the main EPS components in stable granules (Zhang et al. 2019).

EPS production of the granular sludge in a sequential batch reactor increased during the formation of the granules and the PN were the main component of the EPS in the whole bio-granulation process (Wei et al. 2018). The amount of PN was 3.9 times higher than that of PS and contributed to the improvement of the structural stability of the granules (Wei et al. 2018).

\section{Humic acid quantification}

The consortia lacking isolates $1,3,9,10,11,14,15,18,19$, and 24, presented increased humic acid production in the period between 48 and $72 \mathrm{~h}$, related to growth stabilization (Fig. 4).

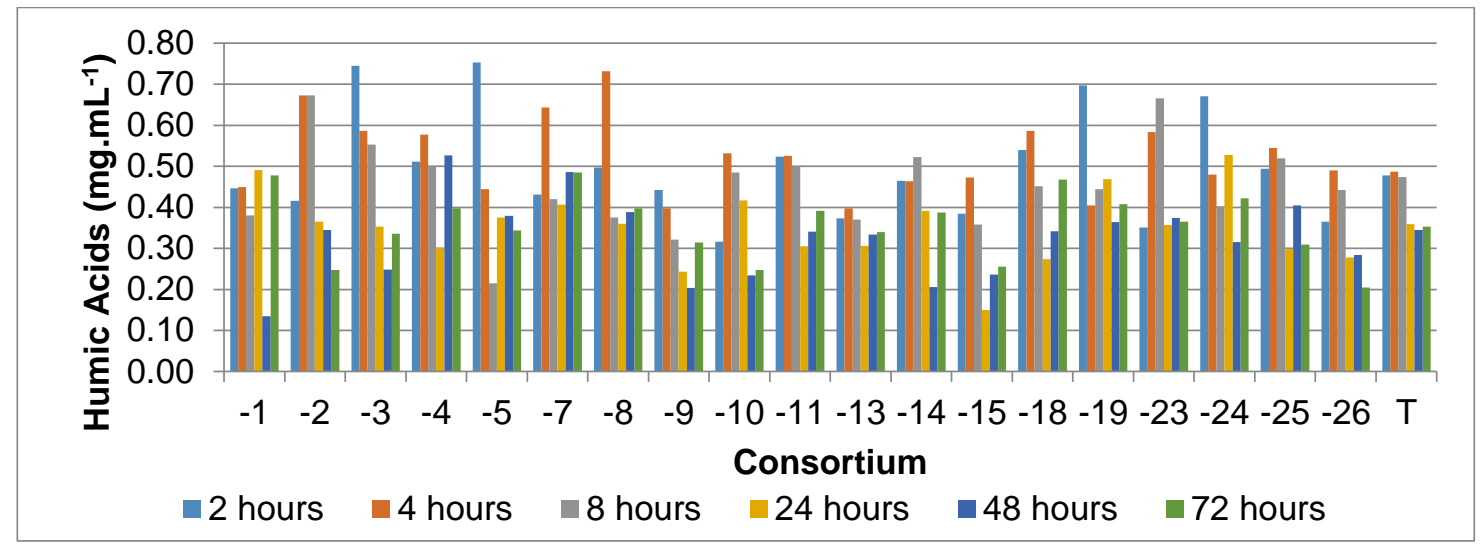

Fig. 4. Concentration of humic acids (mEq. $\mathrm{mL}^{-1}$ of albumin) during co-aggregation experiment. (-n $=$ consortium with absence of the $\mathrm{n}^{\text {th }}$ isolate, $\mathrm{T}=$ control consortium with all isolates)

Consortia with an absence of four isolates (2, 7, 13, and 25), indicated as contributing to aggregate formation (Morais et al. 2016b), showed a reduction or maintenance of humic acid content. Such behavior may indicate that these isolates can act by maintaining or increasing protein concentration, which may favor the formation of more compact and stable aerobic granules. 
On the other hand, the consortia -10 and -26 , with absence of isolates harmful to aggregate formation, had lower concentrations of humic acids in the stage of the microbial growth stabilization (after $48 \mathrm{~h}$ of incubation). Humic acids are mainly derived from the adsorption of compounds present in the medium and hydrolysis of other biopolymers, such as proteins (Zhang et al. 2018). The study by Zhang et al. (2018) indicated that the humic acid-like substances can be detrimental to the stability of the granules. Thus, removal of isolates 10 and 26 may have contributed to improved aggregation.

Humic acids are components of the EPS that are produced during the formation of the aerobic granules. The function of humic acids and proteins, is to act on the granule structure (Gao et al. 2011).

According to the EPS quantifications, the PN/PS rate was determined, which evaluates the relationship between nitrogenous (PN) and polysaccharide (PS) content.

The PN/PS ratio can positively influence hydrophobicity and zeta potential, contributing to the increase in aggregative ability (Zhang et al. 2015). Additionally, granules formed with a PN/PS ratio of less than 1 are susceptible to disaggregation, since cell-cell interactions are weak (Jiang et al. 2002; Liu et al. 2004; Zhang et al. 2015).

The consortia $-4,-10,-14,-18$, which do not contain the isolates harmful to granulation, were absent, presented, except for -26 , a PN/PS ratio $\geq 1$ (Table 2). A higher PN/PS ratio enhances hydrophobicity and contributes to greater aggregation and stability of the aggregates (Zhang et al. 2015, 2018). In addition, the higher PN content may be related to the stabilization of aggregates and PS consumption due mainly to the reduction of substrate in the internal layers of the granules, which leads to the consumption of the easily biodegradable EPS components, especially polysaccharides.

Table 2. Nitrogenous (PN)/polysaccharide (PS) Substance Ratios from the EPS Extracted from the Samples after $72 \mathrm{~h}$ of Consortia Growth, in Liquid R2A Medium, (aeration at $30 \pm 1^{\circ} \mathrm{C}$ in the dark)

\begin{tabular}{|c|c|}
\hline PN/PS & Consortia \\
\hline $\mathbf{1 . 8 0}$ & -1 \\
\hline $\mathbf{0 . 8 8}$ & -2 \\
\hline $\mathbf{0 . 9 2}$ & -3 \\
\hline $\mathbf{7 . 1 9}$ & -4 \\
\hline $\mathbf{0 . 7 9}$ & -5 \\
\hline $\mathbf{1 . 2 4}$ & -7 \\
\hline $\mathbf{5 . 5 6}$ & -8 \\
\hline $\mathbf{1 . 1 5}$ & -9 \\
\hline $\mathbf{1 . 7 7}$ & -10 \\
\hline $\mathbf{3 . 4 5}$ & -11 \\
\hline $\mathbf{0 . 7 2}$ & -13 \\
\hline $\mathbf{2 . 3 8}$ & -14 \\
\hline $\mathbf{1 . 0 7}$ & -15 \\
\hline $\mathbf{1 . 0 0}$ & -18 \\
\hline $\mathbf{2 . 3 5}$ & -19 \\
\hline $\mathbf{8 . 4 3}$ & -23 \\
\hline $\mathbf{1 . 9 7}$ & -24 \\
\hline $\mathbf{1 . 5 7}$ & -25 \\
\hline $\mathbf{0 . 7 8}$ & -26 \\
\hline & \\
\hline
\end{tabular}


The PN/PS ratio of the granules is higher than that of the activated sludge (Sajjad and Kim, 2015; Zhu et al. 2015). Aerobic granules presented higher protein content (PN/PS between 1.4 and 1.6), while flocs had higher polysaccharide content (PN/PS $=0.5$ ) (Basuvaraj et al. 2015). The PN/PS ratio may vary throughout the granule formation process. During simultaneous nitrogen and phosphorus removal in a reactor with granular

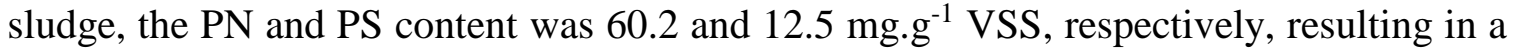
PN/PS ratio of 4.8. During granule formation there was an increase in the concentration of $\mathrm{PN}$ and PS and in the PN/PS ratio. The matured granules presented concentrations of 101.1 mg.L. $\mathrm{L}^{-1} \mathrm{PN}$ and $15.8 \mathrm{mg} . \mathrm{L}^{-1} \mathrm{PS}$ after 150 days of reactor operation, corresponding to a PN/PS ratio of 6.4 (Wei et al. 2014). In addition, the chemical composition of EPS was influenced by the feeding COD/N ratio. In the sludge used as inoculum and in the system with $\mathrm{COD} / \mathrm{N}$ equal to 6, there was a predominance of tryptophan PN-like substances and aromatic PN-like substances, respectively, whereas in systems with COD/N equal to 7 and 9 there was a predominance of humic acid-like substances (Wei et al. 2014).

The PN also present higher affinity for cations such as $\mathrm{Ca}^{2+}$ and $\mathrm{Mn}^{2+}$ and facilitate the binding of EPS with these ions, reducing surface charge and promoting cell adhesion (Zhu et al. 2015). The higher affinity of the proteins for cations was also observed in a study of Zn sorption onto aerobic granular sludge. PN-like substances were also more susceptible to $\mathrm{Zn}$ (II) adsorption than humic-like substances (Wei et al. 2016). In addition, increasing the doses of $\mathrm{Zn}$ (II) from 0 to $600 \mathrm{mg} . \mathrm{L}^{-1}$ reduced the PN/PS ratio from 3.98 to 2.32, as well as PN concentrations from 23.55 to $9.55 \mathrm{mg} . \mathrm{g}^{-1} \mathrm{VSS}$ and PS from 5.92 to 4.11 $\mathrm{mg} \cdot \mathrm{g}^{-1}$ VSS (Wei et al. 2016). These results indicate the importance of EPS in ion binding and granule formation.

The isolates favoring the formation of the granules $(2,7,9,13,19$, and 25) belong to four of the five genera identified (Table 3). Bacteria of these four genera are described as producing EPS with characteristics that favor the formation of biofilms and granules (Lv et al. 2014).

Table 3. Identification of the Isolates Favorable to Formation of Aerobic Granules

\begin{tabular}{|c|c|}
\hline Isolate & Identification \\
\hline 2 & Agrobacterium $\mathrm{sp}$. \\
\hline 7 & Enterobacter $\mathrm{sp}$. \\
\hline 9 & Staphylococcus $\mathrm{sp}$. \\
\hline 13 & Agrobacterium $\mathrm{sp}$. \\
\hline 19 & Agrobacterium $\mathrm{sp}$. \\
\hline 25 & Rhodococcus $\mathrm{sp}$. \\
\hline
\end{tabular}

Bacteria of the genera identified in Table 3 are described as producing EPS with characteristics that favor the formation of biofilms and granules.

Enterobacter strains have been reported as producing intracellular adhesion polysaccharides, which are primary substances directly involved in the formation of biofilms and granules (Limoli et al. 2015). An Enterobacter strain demonstrated better EPS production by maintaining the $\mathrm{pH}$ at 7.0 and the temperature at $30{ }^{\circ} \mathrm{C}$ (Torres et al. 2012). The growth curve of Enterobacter aerogenes showed that EPS secretion was parallel to cell growth, with the highest EPS release observed in the initial stationary phase (Salehizadeh and Yan 2014).

The EPS produced by Rhodococcus strains have biofilm protection properties, and some species have been widely used in bioremediation processes to reduce contaminants 
in water and soil (Pen et al. 2015; Rodrigues et al. 2006). Rhodobacteraceae and other organisms with high EPS production, especially tryptophan and protein-like substances, contribute to microbial aggregation (Zhang et al. 2019). Rhodobacter spp., Thauera spp., and Pseudoxanthomonas spp. were the main microrganisms for stable granules in two bioreactors with different $\mathrm{C} / \mathrm{N}$ ratios. These microorganisms were related to high EPS secretion and the increased hydrophobicity of the granules (Zhang et al. 2018).

Isolates from Agrobacterium sp. were observed on the surface of granules and generated large amounts of protein and flocculants. In addition, the use of phosphorus in the production of EPS of Agrobacterium strains was evaluated, and it was found that phosphorus limitation increases the production of substances that help in the formation of biofilms and granules by species of this bacterial genus (Huang et al. 2012). The use of phosphorus in the EPS production of Agrobacterium strains was evaluated by Ma et al. (2016). The limitation of phosphorus increases the production of substances that contribute to the formation of biofilms and granules by species of this bacterial genus.

Hydrophobic interactions are important for the coaggregation of Acinetobacter sp. and other sludge-forming bacteria (Phuong et al. 2009).

Isolates from Flavobacterium croceum and Agrobacterium sp. were observed on the surface of granules and generated large amounts of protein and flocculants that contribute to the formation of biofilms and granules (Huang et al. 2012).

Cationic exopolysaccharides such as intercellular adhesin and poly-Nacetylglucosamine found in biofilms of Staphylococcus epidermidis and Staphylococcus aureus, respectively, play an important structural role in biofilms (Seviour et al. 2012). Staphylococcus aureus is a human pathogen that causes a large number of diseases ranging from benign skin infections to fatal conditions such as bacteremia, infective endocarditis, and chronic infections (Haaber et al. 2016). The pathogenicity of S. aureus is related to its high capacity for self-aggregation and to form biofilms. Additionally, S. aureus aggregates efficiently in human plasma, a condition that is related to virulence, and can form planktonic aggregates that protect cells against antibiotics (Haaber et al. 2016).

\section{CONCLUSIONS}

1. Nineteen cultivable isolates were obtained from the mesophilic aerobic granules produced during the proposed treatment. Based on the extracellular polysaccharides (EPS) results, it was noticed that there are differences in the effectiveness of the influence of each isolate on the production of EPS that contributes to granule formation. Among the isolates obtained, six (2, 7, 9, 13, 19 and 25) were indicated as important for the formation and maintenance of the mesophilic aerobic granules.

2. The isolates indicated as important for granule formation were identified as belonging to the genera Agrobacterium, Enterobacter, Rhodococcus and Staphylococcus and are reported in the literature as being high EPS producers, helping in the formation / maintenance of biofilms and granules.

3. The coaggregation test, associated with EPS analysis and quantification, could be used to determine the isolates that effectively contribute to the formation and maintenance of mesophilic aerobic granules. 


\section{ACKNOWLEDGMENTS}

The authors are grateful to the State University of Southwest of Bahia for the Postgraduate Grant to the first author, the Conselho Nacional de Desenvolvimento Científico e Tecnológico (CNPq), the Coordenação de Aperfeiçoamento de Pessoal de Nível Superior (CAPES) and Fundação de Amparo à Pesquisa do Estado de Minas Gerais (FAPEMIG) for the financial support.

\section{REFERENCES CITED}

Adav, S. S., Lee, D.-J., and Lai, J.-Y. (2010). "Potential cause of aerobic granular sludge breakdown at high organic loading rates," Applied Microbiology and Biotechnology, 85(5), 1601-1610. DOI: 10.1007/s00253-009-2317-9

Albalasmeh, A. A., Berhe, A. A., and Ghezzehei, T. A. (2013). "A new method for rapid determination of carbohydrate and total carbon concentrations using UV spectrophotometry," Carbohydrate Polymers 97(2), 253-261. DOI: 10.1016/j.carbpol.2013.04.072

Applied Biosystems. (2016). "POP6 polymer," Foster City.

Basuvaraj, M., Fein, J., and Liss, S. N. (2015). "Protein and polysaccharide content of tightly and loosely bound extracellular polymeric substances and the development of a granular activated sludge floc," Water research, 82, 104-117. DOI: 10.1016/j.watres.2015.05.014

De Carvalho, C. C. C. R., Marques, M. P. C., Fernandes, P., and Da Fonseca, M. M. R. (2005). "A simple imaging method for biomass determination," Journal of Microbiological Methods 60(1), 135-140. DOI: 10.1016/j.mimet.2004.09.014

Caudan, C., Filali, A., Spérandio, M., and Girbal-Neuhauser, E. (2014). "Multiple EPS interactions involved in the cohesion and structure of aerobic granules," Chemosphere 117(1), 262-270. DOI: 10.1016/j.chemosphere.2014.07.020

Frolund, B., Palmgren, R., Keiding, K., and Nielsen, P. H. (1996). "Extraction of extracellular polymers from activated sludge using a cation exchange resin," Water Research 30, 1749-1758.

Gao, D., Fu, Y., Tao, Y., Li, X., Xing, M., Gao, X., and Ren, N. (2011). "Linking microbial community structure to membrane biofouling associated with varying dissolved oxygen concentrations," Bioresource Technology 102(10), 5626-5633. DOI: http://dx.doi.org/10.1016/j.biortech.2011.02.039

Haaber, J., Cohn, M. T., Petersen, A., and Ingmer, H. (2016). "Simple method for correct enumeration of Staphylococcus aureus," Journal of Microbiological Methods 125, 58-63. DOI: 10.1016/j.mimet.2016.04.004

Huang, L., Yang, T., Wang, W., Zhang, B., and Sun, Y. (2012). "Effect of $\mathrm{Mn}^{2+}$ augmentation on reinforcing aerobic sludge granulation in a sequencing batch reactor," Applied Microbiology and Biotechnology 93(6), 2615-2623. DOI: 10.1007/s00253-011-3555-1

Ivanov, V., Wang, X. H., Tay, S. T. L., and Tay, J. H. (2006). "Bioaugmentation and enhanced formation of microbial granules used in aerobic wastewater treatment," Applied Microbiology and Biotechnology 70(3), 374-381. DOI: 10.1007/s00253-0050088-5 
Jiang, H. L., Tay, J. H., and Tay, S. T. L. (2002). "Aggregation of immobilized activated sludge cells into aerobically grown microbial granules for the aerobic biodegradation of phenol," Letters in Applied Microbiology, 35, 439-445.

Kennedy, J., Codling, C. E., Jones, B. V, Dobson, A. D. W., and Marchesi, J. R. (2008). "Diversity of microbes associated with the marine sponge, Haliclona simulans, isolated from Irish waters and identification of polyketide synthase genes from the sponge metagenome," Environmental Microbiology 10(7), 1888-1902. DOI: 10.1111/j.1462-2920.2008.01614.x

Khan, M. Z., Khan, F., and Sabir, S. (2011). "Aerobic granular treatment of 2,4dichlorophenol," Canadian Journal of Chemical Engineering 89(4), 914-920. DOI: $10.1002 /$ cjce. 20445

Kim, K. S., Sajjad, M., Lee, J., Park, J., and Jun, T. (2014). "Variation of extracellular polymeric substances (EPS) and specific resistance to filtration in sludge granulation process to the change of influent organic loading rate," Desalination and Water Treatment 52(22-24), 4376-4387. DOI: 10.1080/19443994.2013.801795

Klebensberger, J., Rui, O., Fritz, E., Schink, B., and Philipp, B. (2006). "Cell aggregation of Pseudomonas aeruginosa strain PAO1 as an energy-dependent stress response during growth with sodium dodecyl sulfate," Archives of Microbiology 185(6), 417 427. DOI: 10.1007/s00203-006-0111-y

Di Laconi, C., Ramadori, R., and Lopez, A. (2006). "Combined biological and chemical degradation for treating a mature municipal landfill leachate," Biochemical Engineering Journal, 31, 118-124.

Li, Y., Zou, J., Zhang, L., and Sun, J. (2014). “Aerobic granular sludge for simultaneous accumulation of mineral phosphorus and removal of nitrogen via nitrite in wastewater," Bioresource Technology 154(2), 178-184. DOI: 10.1016/j.biortech.2013.12.033

Limoli, D. H., Jones, C. J., and Wozniak, D. J. (2015). "Bacterial extracellular polysaccharides in biofilm formation and function," Microbiology Spectrum 3(3), 11 28. DOI: 10.1128/microbiolspec.MB-0011-2014

Liu, Y.-Q., Liu, Y., and Tay, J.-H. (2004). "The effects of extracellular polymeric substances on the formation and stability of biogranules," Applied Microbiology and Biotechnology 65(2), 143-148. DOI: 10.1007/s00253-004-1657-8

Liu, Y. Q., and Tay, J. H. (2007). "Influence of cycle time on kinetic behaviors of steadystate aerobic granules in sequencing batch reactors," Enzyme and Microbial Technology 41(4), 516-522. DOI: 10.1016/j.enzmictec.2007.04.005

Lv, Y., Wan, C., Lee, D. J., Liu, X., and Tay, J. H. (2014). "Microbial communities of aerobic granules: Granulation mechanisms," Bioresource Technology 169, 344-351. DOI: 10.1016/j.biortech.2014.07.005

Ma, T., Chen, Q., Gui, M., Li, C., and Ni, J. (2016). "Simultaneous denitrification and phosphorus removal by Agrobacterium sp. LAD9 under varying oxygen concentration," Applied Microbiology and Biotechnology 100(7), 3337-3346. DOI: 10.1007/s00253-015-7217-6

Maszenan, A. M., Liu, Y., and Ng, W. J. (2011). "Bioremediation of wastewaters with recalcitrant organic compounds and metals by aerobic granules," Biotechnology Advances 29(1), 111-123. DOI: 10.1016/j.biotechadv.2010.09.004

McSwain, B. S., Irvine, R. L., Hausner, M., and Wilderer, P. a. (2005). "Composition and distribution of extracellular polymeric substances in aerobic flocs and granular 
sludge," Applied and Environmental Microbiology 71(2), 1051-1057. DOI:

10.1128/AEM.71.2.1051

Morais, I. L. H., Silva, C. M., and Borges, C. P. (2016a). "Aerobic granular sludge to treat paper mill effluent: organic matter removal and sludge filterability," Desalination and Water Treatment 57(18), 8119-8126. DOI: 10.1080/19443994.2015.1022803

Morais, I. L. H., Silva, C. M., Nascimento, A. G. do, Filho, N. P., and Dias, J. C. T. (2016b). "Aerobic granular sludge to treat paper mill effluent: Selection of ideal strains that contribute to the formation of strong aggregates," Desalination and Water Treatment 57(59), 28537-28550. DOI: 10.1080/19443994.2016.1192490

Myers, J. A., Curtis, B. S., and Curtis, W. R. (2013). "Improving accuracy of cell and chromophore concentration measurements using optical density," BMC Biophysics, 6(1), 4. DOI: 10.1186/2046-1682-6-4

NCBI. (2015). "Standard Nucleotide BLAST," $<$ https://blast.ncbi.nlm.nih.gov/Blast.cgi?PROGRAM=blastn\&PAGE_TYPE=BlastSe arch\&LINK_LOC=blasthome> (Oct. 16, 2015).

Pen, Y., Zhang, Z. J., Morales-Garcia, A. L., Mears, M., Tarmey, D. S., Edyvean, R. G., Banwart, S. A., and Geoghegan, M. (2015). "Effect of extracellular polymeric substances on the mechanical properties of Rhodococcus," Biochimica et Biophysica Acta 1848(2), 518-526. DOI: 10.1016/j.bbamem.2014.11.007

Phuong, K., Kakii, K., and Nikata, T. (2009). "Intergeneric coaggregation of nonflocculating Acinetobacter spp. isolates with other sludge-constituting bacteria," Journal of Bioscience and Bioengineering 107(4), 394-400. DOI: 10.1016/j.jbiosc.2008.11.020

Rodrigues, J. L. M., Kachel, C. A., Aiello, M. R., Quensen, J. F., Maltseva, O. V, Tsoi, T. V, and Tiedje, J. M. (2006). "Degradation of Aroclor 1242 dechlorination products in sediments by Burkholderia xenovorans LB400(ohb) and Rhodococcus sp. strain RHA1(fcb)," Applied and Environmental Microbiology 72(4), 2476-2482. DOI: 10.1128/AEM.72.4.2476-2482.2006

Sajjad, M., and Kim, K. S. (2015). "Influence of $\mathrm{Mg}^{2+}$ catalyzed granular sludge on flux sustainability in a sequencing batch membrane bioreactor system," Chemical Engineering Journal 281, 404-410. DOI: 10.1016/j.cej.2015.06.112

Salehizadeh, H., and Yan, N. (2014). "Recent advances in extracellular biopolymer flocculants," Biotechnology Advances 32(8), 1506-1522. DOI:

10.1016/j.biotechadv.2014.10.004

Seviour, T., Yuan, Z., van Loosdrecht, M. C. M., and Lin, Y. (2012). "Aerobic sludge granulation: A tale of two polysaccharides?," Water Research 46(15), 4803-4813. DOI: $10.1016 /$ j.watres.2012.06.018

Shimadzu®. (2016). “Total Organic Carbon Analyzer,” Kyoto.

Tay, J.-H., Ivanov, V., Pan, S., and Tay, S. T.-L. (2002). "Specific layers in aerobically grown microbial granules," Letters in Applied Microbiology 34(4), 254-257.

Toh, S. K., Tay, J. H., Moy, B. Y. P., Ivanov, V., and Tay, S. T. L. (2003). "Size-effect on the physical characteristics of the aerobic granule in a SBR," Applied Microbiology and Biotechnology 60(6), 687-695. DOI: 10.1007/s00253-002-1145-y

Torres, C. A. V, Antunes, S., Ricardo, A. R., Grandfils, C., Alves, V. D., Freitas, F., and Reis, M. A. M. (2012). "Study of the interactive effect of temperature and $\mathrm{pH}$ on exopolysaccharide production by Enterobacter A47 using multivariate statistical 
analysis," Bioresource Technology 119, 148-156.

DOI:10.1016/j.biortech.2012.05.106

Tu, X., Su, B., Li, X., and Zhu, J. (2010). "Characteristics of extracellular fluorescent substances of aerobic granular sludge in pilot-scale sequencing batch reactor," Journal of Central South University of Technology 17(3), 522-528. DOI: 10.1007/s11771-010-0517-1

Wan, C., Lee, D. J., Yang, X., Wang, Y., Wang, X., and Liu, X. (2015). "Calcium precipitate induced aerobic granulation," Bioresource Technology 176, 32-37. DOI: 10.1016/j.biortech.2014.11.008

Wan, C., Shen, Y., Chen, S., Liu, X., Liu, G., Lai, J.-Y., and Lee, D.-J. (2016). "Microstructural strength deterioration of aerobic granule sludge under organic loading swap," Bioresource Technology 221, 671-676. DOI: 10.1016/j.biortech.2016.09.056

Wei, D., Li, M., Wang, X., Han, F., Li, L., Guo, J., Ai, L., Fang, L., Liu, L., Du, B., and Wei, Q. (2016). "Extracellular polymeric substances for Zn (II) binding during its sorption process onto aerobic granular sludge," Journal of Hazardous Materials 301(September 2015), 407-415. DOI: 10.1016/j.jhazmat.2015.09.018

Wei, D., Ngo, H. H., Guo, W., Xu, W., Du, B., and Wei, Q. (2018). "Partial nitrification granular sludge reactor as a pretreatment for anaerobic ammonium oxidation (Anammox): Achievement, performance and microbial community," Bioresource Technology 269(June), 25-31. DOI: 10.1016/j.biortech.2018.08.088

Wei, D., Shi, L., Yan, T., Zhang, G., Wang, Y., and Du, B. (2014). “Aerobic granules formation and simultaneous nitrogen and phosphorus removal treating high strength ammonia wastewater in sequencing batch reactor," Bioresource Technology 171(1), 211-216. DOI: 10.1016/j.biortech.2014.08.001

Wei, D., Wang, B., Ngo, H. H., Guo, W., Han, F., Wang, X., Du, B., and Wei, Q. (2015). "Role of extracellular polymeric substances in biosorption of dye wastewater using aerobic granular sludge," Bioresource Technology 185, 14-20. DOI: 10.1016/j.biortech.2015.02.084

Weissbrodt, D. G., Neu, T. R., Kuhlicke, U., Rappaz, Y., and Holliger, C. (2013). "Assessment of bacterial and structural dynamics in aerobic granular biofilms," Frontiers in Microbiology 4(July), 1-18. DOI: 10.3389/fmicb.2013.00175

Xie, W. M., Qiao, L. L., Fang, F., Li, W. W., Meng, H., Wang, G. X., and Zhang, L. M. (2019). "Dynamic characteristics of soluble microbial products in a granular sludge reactor," Journal of Cleaner Production 212, 576-581. DOI: 10.1016/j.jclepro.2018.12.082

Xuan, W., Bin, Z., Zhiqiang, S., Zhigang, Q., Zhaoli, C., Min, J., Junwen, L., and Jingfeng, W. (2010). "The EPS characteristics of sludge in an aerobic granule membrane bioreactor," Bioresource Technology 101(21), 8046-8050. DOI: 10.1016/j.biortech.2010.05.074

Yang, H., Ma, H., Shi, B., Li, L., and Yan, W. (2016). "Experimental study of the effects of heavy metal ions on the hydrogen production performance of Rhodobacter sphaeroides HY01," International Journal of Hydrogen Energy 41(25), 1063110638. DOI: 10.1016/j.ijhydene.2016.04.199

Zhang, H., Yu, H., Zhang, L., and Song, L. (2015). "Stratification structure of polysaccharides and proteins in activated sludge with different aeration in membrane bioreactor," Bioresource Technology, 192, 361-366. DOI:

10.1016/j.biortech.2015.05.025 
Zhang, X., Bishop, P. L., and Kinkle, B. K. (1999). "Comparison of extraction methods for quantifying extracellular polymers in biofilms," Water Science and Technology, 39(7), 211-218. DOI: 10.1016/S0273-1223(99)00170-5

Zhang, Z., Yu, Z., Dong, J., Wang, Z., Ma, K., Xu, X., Alvarezc, P. J. J., and Zhu, L. (2018). "Stability of aerobic granular sludge under condition of low influent $\mathrm{C} / \mathrm{N}$ ratio: Correlation of sludge property and functional microorganism," Bioresource Technology 270, 391-399. DOI: 10.1016/j.biortech.2018.09.045

Zhang, Z., Yu, Z., Wang, Z., Ma, K., Xu, X., Alvarezc, P. J. J., and Zhu, L. (2019). "Understanding of aerobic sludge granulation enhanced by sludge retention time in the aspect of quorum sensing," Bioresource Technology 272, 226-234. DOI: 10.1016/j.biortech.2018.10.027

Zhu, L., Qi, H. y., Lv, M. L., Kong, Y., Yu, Y. W., and Xu, X. Y. (2012). “Component analysis of extracellular polymeric substances (EPS) during aerobic sludge granulation using FTIR and 3D-EEM technologies," Bioresource Technology 124, 455-459. DOI: 10.1016/j.biortech.2012.08.059

Zhu, L., Zhou, J., Lv, M., Yu, H., Zhao, H., and Xu, X. (2015). “Specific component comparison of extracellular polymeric substances (EPS) in flocs and granular sludge using EEM and SDS-PAGE," Chemosphere 121, 26-32. DOI: http://dx.doi.org/10.1016/j.chemosphere.2014.10.053

Article submitted: October 12, 2018; Peer review completed: December 15, 2018;

Revisions accepted: May 24, 2019; Published: June 10, 2019.

DOI: 10.15376/biores.14.3.5845-5861 